REVIEW

\title{
A multi-layered approach to the diversification of squirrels
}

Iris MENÉNDEZ* Departamento de Geodinámica, Estratigrafía y Paleontología, Facultad de Ciencias Geológicas, Universidad Complutense de Madrid, C/ José Antonio Novais 12, Madrid, 28040, Spain and Departamento de Cambio Medioambiental, Instituto de Geociencias (UCM, CSIC), C/Severo Ochoa 7, Madrid, 28040, Spain. Email: irismene@ucm.es

Ana Rosa GÓMEZ CANO Transmitting Science, C/Gardenia 2, Piera, Barcelona, 08784, Spain. Email: argomez@ucm.es

Juan L. CANTALAPIEDRA Departamento de Ciencias de la Vida, GloCEE Global Change Ecology and Evolution Research Group, Universidad de Alcalá, Plaza de San Diego s/n, Alcalá de Henares, Madrid, 28801, Spain. Email: jlopezcant@gmail.com

Pablo PELÁEZ-CAMPOMANES Departameto de Paleobiología, Museo Nacional de Ciencias Naturales, MNCN-CSIC, C/ José Gutiérrez Abascal, 2, Madrid, 28006, Spain. Email: pablopelaez@mncn.csic.es María Ángeles ÁLVAREZ-SIERRA Departamento de Geodinámica, Estratigrafía y Paleontología, Facultad de Ciencias Geológicas, Universidad Complutense de Madrid, Cl José Antonio Novais 12, Madrid, 28040, Spain and Departamento de Cambio Medioambiental, Instituto de Geociencias (UCM, CSIC), C/Severo Ochoa 7, Madrid, 28040, Spain. Email: masierra@ucm.es Manuel HERNÁNDEZ FERNÁNDEZ Departamento de Geodinámica, Estratigrafía y Paleontología, Facultad de Ciencias Geológicas, Universidad Complutense de Madrid, Cl José Antonio Novais 12, Madrid, 28040, Spain and Departamento de Cambio Medioambiental, Instituto de Geociencias (UCM, CSIC), C/Severo Ochoa 7, Madrid, 28040, Spain. Email: hdezfdez@ucm.es

\section{Keywords}

biome specialisation, evolutionary radiation, macroecology, phylogeny, Sciuridae,

state-dependent diversification

${ }^{\star}$ Correspondence author

Received: 18 February 2020

Accepted: 11 June 2020

Editor: DR

doi: 10.1111/mam.12215

\section{ABSTRACT}

1. The shape of the tree of life is the result of shifting diversification rates, and identifying the factors driving these shifts is one of the main aims in evolutionary biology. Various biotic and abiotic factors have been proposed to have an impact on mammal diversification, such as climatic and tectonic changes, the acquisition of new traits, and expansion into new ecosystems or landmasses.

2. We used phylogenetic comparative methods to quantify the influence of potential drivers on diversification patterns in extant squirrels (Sciuridae, Rodentia). We conducted a multilayer approach, comparing diversification rates among squirrel lineages depending on their degree of biome specialisation, biogeographic realm occupancy, locomotion adaptations, and presence in mountainous regions.

3. We generated the most complete phylogeny of squirrels to date, encompassing almost $80 \%$ of the extant species, and applied multiple and binary statedependent diversification models. All the traits examined showed an influence on diversification rates.

4. The biome specialist lineages showed the highest speciation rates, suggesting a major role of bioclimatic specialisation on macroevolutionary patterns. A single major event, the Miocene-Pleistocene radiation of terrestrial-adapted lineages in North America, left a signal that was recovered in two of our analyses. Both the Nearctic lineages and the terrestrial-adapted lineages showed high speciation rates, highlighting the fact that that major evolutionary episodes may produce confounding effects in state-dependent diversification models. 
5. Ancestral reconstructions showed that cold and warm intervals in Earth's history had different effects on squirrels' diversification, depending on their climatic affinities. Tropical and arboreal squirrels evolved predominantly in the warm intervals, while terrestrial and cold-adapted squirrels radiated in the cold intervals.

6. Our findings suggest that, while global climatic shifts are key for the speciation processes in mammalian lineages, lineage-specific ecological adaptations are critical modulators of the responses of lineages to such environmental shifts, in an interplay that ultimately affects their diversification patterns.

\section{INTRODUCTION}

One of the main aims of macroevolutionary research is to explain why the tree of life is so unbalanced: some lineages show astonishing species diversity, while others have just one or a few representatives extending from very long branches (Rabosky et al. 2012). This unevenness is the outcome of a marked tree-wide variation in speciation and extinction rates (Simpson 1944), which is believed to result from complex interactions between biotic and abiotic factors operating over macroevolutionary time-scales (Simões et al. 2016). Such factors may include differential state-dependent diversification (Jablonski 2008), the invasion of unused ecological space (Simpson 1944), changes in biogeographic settings (Marshall \& Quental 2016, Cantalapiedra et al. 2017), competition (Silvestro et al. 2015), and shifts in physical factors such as climate (Vrba 1995), tectonics (Finarelli \& Badgley 2010), and habitat heterogeneity (Vrba 1992). Yet, despite the growing interest in macroevolutionary rates and the bloom of new quantitative methods in the last two decades, most of the studies that explore the drivers of clades' diversification focus on one aspect of the many that could shape trees over evolutionary time-scales (e.g. Cantalapiedra et al. 2014a, Feldman et al. 2016).

Using multi-layered approaches to reveal how the many potential drivers have interplayed to shape the diversity patterns that we observe in the fossil record and in molecular evolutionary trees is key to understanding the evolution of lineages and biotas in the past, and has implications for understanding the present and future of our planet's diversity (Fritz et al. 2013). This is the aim of the present study.

We focused on the diversification patterns of squirrels (family Sciuridae). Squirrels are a good model for macroevolutionary studies due to their widespread distribution and their high species and morphological diversity. Since its origin in Eocene times, around 36 million years ago (Ma; Emry \& Thorington 1982), the squirrels' lineage has evolved into disparate ecomorphological types and has spread into all of the world's biomes and all the continents except Antarctica and Australia. Their diversity, with almost three hundred extant species (Koprowski et al. 2016, Wauters et al. 2017, Mori et al. 2018), and their wide variety of adaptations make the evolutionary radiation of squirrels an exceptional case for assessing the combined contribution of intrinsic and extrinsic factors in shaping unbalanced phylogenies. Although many studies have linked speciation events of some clades within Sciuridae to geological and climatic conditions (Harrison et al. 2003, Mercer \& Roth 2003, Roth \& Mercer 2008, Ge et al. 2014, Zelditch et al. 2015), these notions have never been formally tested using comparative analyses.

We inferred a new molecular phylogeny of squirrels with 225 species based on GenBank sequences. We also gathered extensive information from the literature about squirrel species': 1) bioclimatic tolerances (based on biome occupancy); 2) occupancy of mountainous regions (which may suggest isolation in mountainous regions); 3) biogeographic realm occupancy; and 4) locomotion mode, which encapsulates multiple aspects of their functional ecology. We used phylogenetic likelihood modelling to ask whether such factors have impacted diversification rates across squirrels' phylogeny. In particular, for each of these factors, our expectations were the following:

1. Over geological time-scales, biomes move, shrink, stretch, and break up tracking broad climate shifts, so the geographic distributions of biome generalists (species inhabiting several biomes) should show more stability and lower fragmentation than those of biome specialists (species restricted to a single biome). Thus, biome specialists are expected to show higher speciation and extinction rates than more bioclimatically tolerant species (Vrba 1987, 1992, Hernández Fernández \& Vrba 2005, Gómez Cano et al. 2013).

2. Lineages inhabiting mountainous regions should have higher diversification rates than lineages found exclusively in lowlands, due to habitat heterogeneity (Marshall \& Quental 2016) and the presence of dispersal barriers 
associated with the elevational gradient and its interaction with climatic changes (Vrba 1992, Badgley 2010).

3. Diversification of squirrels should be biogeographically mediated. Arrival at the different land masses has been suggested as a major driver of differential diversification in squirrel lineages (Mercer \& Roth 2003, Roth 2005). The connections between landmasses allow the species to occupy new biogeographic realms, which differ in their climatic structure, tectonic conditions, historical contingency, and ecological setups (Jetz et al. 2012). The interaction of all these factors should result in disparate evolutionary scenarios where lineages show different diversification rates (Marshall \& Quental 2016).

4. If the development of different functional plans, here condensed into locomotion modes, promotes the invasion of opening adaptive landscapes (Simpson 1944), some of the locomotion modes should show higher species multiplication than others. For example, Zelditch et al. (2015) suggest that high speciation rates in North American squirrels may be linked to their terrestrial locomotion.

These predictions involve intrinsic and extrinsic factors operating at different scales. Such factors usually interact and, therefore, need to be studied in the same framework. This is especially so in squirrels, whose ecological versatility is better explained by the combination of different traits than by any single trait or traits that covary (Roth 2005). We therefore built state-dependent models for the different traits and analysed the relationships between them, which allowed us to discuss their relative contribution to the diversification patterns observed. The study of why, when, and where the diversification rates shifted will help us to understand whether such changes were caused by intrinsic or extrinsic factors, or a mixture of both (Benton 2009).

\section{METHODS}

\section{Phylogenetic reconstruction}

In order to maintain internal consistency for species data, we used the last accepted taxonomy, which includes 292 squirrel species (Koprowski et al. 2016). We developed a new phylogeny of Sciuridae based on the work presented by Zelditch et al. (2015) and on recent DNA information gathered for molecular studies. We added 275 new sequences from Genbank (https://www.ncbi.nlm. nih.gov/genbank/; sequences wrongly assigned to Sciuridae are listed in Appendix S1) for the five mitochondrial genes (16S, 12S, COII, COIII, and Cyt-b) and three nuclear genes (C-myc, IRBP, and RAG1) to the sequences used by Zelditch et al. (2015; Appendix S2).
This allowed us to include 225 species, adding 36 species to the most complete phylogeny to date (Zelditch et al. 2015).

We aligned each gene independently with the online application MAFFT 7 (Katoh \& Toh 2008), applying the default parameters. Then, gene sequences were concatenated using Geneious v. 8 (http://www.geneious.com; Kearse et al. 2012) and checked by eye. The best partitioning and substitution models were inferred using PartitionFinder (Lanfear et al. 2012) with the following parameters: linked branch length, BEAST models, Bayesian Information Criterion model selection, and greedy scheme search. Each gene was established as a data block. The GTR + I + G + X was the model selected for all partitions (12s; 16s; COI, COII, COII; CYTB), except for the SYM $+I+G$ which was selected for the partition of nuclear genes (CMYC, RAG1, IRBP).

We conducted phylogenetic analyses under maximum likelihood and Bayesian inference frameworks. The maximum likelihood analysis was performed using RaxML v8.2.8 (Stamatakis 2014) as implemented in raxmlGUI v.1.3 (Silvestro \& Michalak 2012). As the software only allows a single model of rate heterogeneity, we used the GTR + G model for all partitions. We performed 100 inferences, and clade support was assessed using a nonparametric bootstrap procedure with 1000 replicates. The Bayesian inference analysis was performed using BEAST 1.8.0 (Drummond \& Rambaut 2007). We selected an uncorrelated log-normal relaxed clock for all mitochondrial partitions and a strict clock for the nuclear partition. A Yule process was selected as tree prior.

The use of multiple calibration points is crucial to infer correct divergence times for phylogenies (Sauquet et al. 2012). Therefore, following the recommendations of Sauquet et al. (2012) and Parham et al. (2012), we carried out an extensive review of extinct squirrel species to select reliable calibration points and provide a reference list for all of them (Appendix S3). Finally, 10 calibration points distributed along clades and periods were included in the following nodes: Sciuroidea, Sciuridae, Sciurini (stem), Marmotini (stem), Xerini, Callosciurus, Funambulus, Marmota, Paraxerus, Tamiops, and Hylopetes (Appendix S3).

The prior distribution for calibration points was gamma-shaped (2) and scaled at $1 \%$ of the offset (minimum age). Nevertheless, for the base of the tree (Sciuroidea) we specified maximum and minimum ages using a normal distribution adjusted to the age range between two dated fossils (inside 2.5\% quantiles; Appendix S3). We performed two independent Markov chain Monte Carlo analyses with 200 million iterations on the CIPRES Science Gateway (http://www.phylo.org; Miller et al. 2010). The adequateness of the effective 
sampling sizes $(>200)$ and the correct convergence of the two chains were assessed using Tracer version 1.6 (Rambaut et al. 2014). Posterior trees from the two runs were combined after discarding $10 \%$ as burn-in using LogCombiner 1.8.0, and the maximum credibility consensus tree was generated with TreeAnnotator (both provided with the BEAST package). Nodes were considered as well supported when bootstrap values $\geq 70 \%$ and posterior values $\geq 0.95$.

\section{Trait characterisation}

Biomes reflect multiple biotic and abiotic aspects that are important for the maintenance of the populations inhabiting them (Hernández Fernández \& Vrba 2005). We recorded biome occupancy for all extant squirrel species by comparing the geographic range of each species (Koprowski et al. 2016) with the distribution of biomes following the classification by Walter (1970; Appendix S4). Following Hernández Fernández (2001), the biomes occupied by a species were recorded as a function of the relative size of the climatic zones that species inhabited, in comparison with the size of its geographic range. A species was considered to occupy a specific climatic zone if it inhabited $50 \%$ or more of that climatic zone, or if $15 \%$ or more of its geographic range was situated within a biome. In mountainous regions, we can recognise several vegetation belts; these were considered to be different biomes when assigning mountain species into biomes (Hernández Fernández \& Vrba 2005).

To calculate the degree of specialisation, we used the biomic specialisation index (BSI) developed by Hernández Fernández and Vrba (2005) and based on the number of biomes occupied by each species (BSI from 1 to 10). The BSI is a reliable measure of species' ecological specialisation (Hernández Fernández \& Vrba 2005, Moreno Bofarull et al. 2008, Cantalapiedra et al. 2011, Gómez Cano et al. 2013), which allows comparison of multiple taxa or biogeographic contexts while reducing the bias for rare and less-sampled taxa. We considered three groups of specialisation (Hernández Fernández \& Vrba 2005) that appear to be associated with distinct evolutionary behaviours: biome specialists (BSI $=1)$, biome generalists $(1<$ BSI $<5)$, and extreme biome generalists $($ BSI $\geq 5)$.

We defined species as occupying mountain ranges when their elevational ranges (Koprowski et al. 2016, IUCN 2020) showed that they inhabited vegetation belts that differed from those present in the surrounding lowlands (defined as areas below $1000 \mathrm{~m}$ elevation).

We also assigned each species to one biogeographic realm based on its geographic range (Koprowski et al. 2016): Nearctic, Neotropical, Palaearctic, Afrotropical, and Indomalayan (Appendix S4). The limits of the biogeographic realms were taken from Cantalapiedra et al. (2014b). For the few species recorded in two biogeographic realms, the realm with larger part of the range was recorded.

Finally, locomotion mode for each species was recorded as terrestrial, gliding, or arboreal (Roth 2005). In squirrels, locomotion habits (among other morphological traits; e.g. Ancillotto \& Mori 2017) condense several ecological dimensions, such as the use and exploitation of the space and the feeding strategy.

\section{State-dependent diversification analyses}

To test whether changes in the different factors considered had an impact on squirrels' diversification rates, we ran likelihood-based models with functions in the Diversitree package (FitzJohn 2012) implemented in R ( R Core Team 2008). We compared models where diversification was allowed to change among different character states with null models where the diversification rate was kept constant in all the lineages of the tree. We selected the best models as those with the lowest Akaike Information Criterion scores, considering that a given model has a significantly better fit than another model when the difference in Akaike Information Criterion scores between them is greater than two units.

For the degree of biome specialisation, biogeographic realms, and locomotion mode analyses, we used Multiple State Speciation and Extinction Models to compare speciation rates between multiple qualitative states (FitzJohn 2012). We repeated the analysis for two different evolutionary models. In the first model, we allowed all transitions between states $(0<->1,0<->2$, $1<->2$ ). In the second (constrained) model, we only allowed transitions to take place through the intermediate state $(0<->1<->2)$. The categories used for biomic specialisation were the following: (0) specialist, (1) generalist, and (2) extreme generalist. For the locomotion modes, we assigned: (0) gliding, (1) arboreal, and (2) terrestrial. For the biogeographic realms, we assigned five states: Neotropical (0), Nearctic (1), Palaearctic (2), Afrotropical (3), Indomalayan (4), and our constrained model only allowed transitions based on geographic proximity (Appendix S4; $0<->1<->2<->3<->4<->2$ ). For the analysis of the trait representing presence in mountain ranges, we used the Binary State Speciation and Extinction Model (Maddison et al. 2007), which is similar to the multiple state model but reduced to two states (exclusive lowland inhabitants, and mountain inhabitants). Finally, an ancestral reconstruction was calculated based on the best model for each trait. We ran 3000 iterations for each analysis, and the correct convergence was verified using Tracer version 1.6 (Rambaut et al. 2014). 


\section{Relationships between traits}

Ecological affinities of squirrel lineages are better explained by a combination of traits than by any single trait (Roth 2005). Nevertheless, there might be traits that covary, showing redundant information, or traits that are never linked. We explored this issue through two different analyses.

In order to explore the relationship among traits, we performed a chi-squared test that informed us which traits are linked and which ones are independent from each other, as well as which states from different traits are more closely related (states that are frequently present together in one species). In order to determine whether or not states covary in the phylogeny, we correlated the percentages of each state at every node in the ancestral reconstruction.

\section{RESULTS AND DISCUSSION}

\section{Phylogeny}

The phylogenetic tree we constructed included almost $80 \%$ of extant species of Sciuridae $(n=225)$, and $98 \%$ of the genera ( 59 out of 60 , as in previous works). The sampling, however, was unbalanced: the phylogeny includes more Holarctic and terrestrial squirrels than arboreal squirrels from the tropics (Appendix S5), as these species have been less intensively studied (Hawkins et al. 2016, Mendes et al. 2019).

Maximum likelihood analyses yielded similar topology to Bayesian inference (Appendix S6). Nevertheless, Bayesian inference analyses yielded a more robust topology (148 well-supported nodes [66\%], posterior values $<0.95$; Appendix S7) than the maximum likelihood tree ( 80 wellsupported nodes [36\%], bootstrap values $<70 \%$; Appendix S8). The topology obtained is highly congruent with previous inferences (Roth \& Mercer 2008, Fabre et al. 2012, Zelditch et al. 2015). At the subfamily level, our phylogenetic inference supports the relationships reported by Fabre et al. (2012), which placed Xerinae as sister taxon of Callosciurinae, while Roth and Mercer (2008) obtained Xerinae as sister taxon of Sciurinae, and Zelditch et al. (2015) obtained Sciurinae as sister taxa of Callosciurinae. These inconsistencies are probably due to a fast split between the three major groups in a relatively short period of time. The addition of new molecular sequences, mostly included in Callosciurinae, contributed to resolving the problematic relationships within some of the paraphyletic genera obtained by Zelditch et al. (2015; Hyosciurus and Nannosciurus), but the uncertainties in the Sundasciurus group remained, probably due to taxonomic inconsistencies. Also, Sciurotamias davidianus is inferred as the sister clade to Tamias, which makes sense with the derived characters shared by Sciurotamias and Tamias (Thorington et al. 1998). In the Sciurini tribe, our results support the monophyly of Neotropical species found in previous analyses (Oshida \& Masuda 2000, Pečnerová \& Martínková 2012), but this clade also contains the Nearctic species Sciurus colliaei in our reconstruction. The newly added species from the Neotropics Sciurus aureogaster and Sciurus oculatus clustered within the Nearctic clade. According to our calibration results (Appendices S9 and S10), diversification of crown Sciuridae started around $42 \mathrm{Ma}$, which is earlier than previously reported, but receives good posterior support (Appendix S10).

\section{Factors modulating speciation rates in Sciuridae}

According to our modelling approach, the four traits examined (biome specialisation, biogeographic realm, locomotion mode, and occupancy of mountainous regions) had an impact on the diversification patterns of squirrels (Table 1; Fig. 1; Appendices S11-S14).

\section{BIOME SPECIALISATION}

The parameter estimates show that the degree of biome specialisation was the single most important factor influencing diversification rates in squirrel lineages. Lineages that are restricted to only one biome show the highest speciation rates in all analyses (Table 1; Fig. 1a-d). This finding supports the notion of a major role of bioclimatic specialisation in macroevolutionary trends, as predicted by the resource-use hypothesis (Vrba 1987, 1992). Quantitative support for this prediction has also been found in ruminants (Cantalapiedra et al. 2011). Under this view, abiotic changes have a high impact on the macroevolutionary patterns of squirrels. Due to their dependence on the resources associated with one biome, specialist species are more affected by climatic changes. These species are restricted to a particular biome and, under recurrent climatic forcing, their geographic ranges usually undergo habitat fragmentation. The subsequent isolation of populations may lead to vicariant speciation. On the other hand, biome generalists and extreme generalists have a higher capacity to endure climatic variability, and therefore, they are more resilient to climatic changes. Thus, lineages adapted to several biomes are expected to show lower climate-driven speciation rates (Haile-Selassie et al. 2004, Hernández Fernández \& Vrba 2005, Cantalapiedra et al. 2011, Gómez Cano et al. 2013). This should be especially the case in extreme generalists, lineages with high levels of ecological flexibility, which have been associated with higher persistence over longer 
Table1. Fits of the multiple state speciation and extinction model (MUSSE) and the binary state speciation and extinction model (BiSSE). Summary of model fits for the correlation between the factors (biome specialisation, presence in mountainous regions, biogeographic realms, and locomotion modes) and speciation rates for squirrels. The best model is shown in bold (lowest Akaike Information Criterion). InLik, log likelihood of the fit; D.f., number of degrees of freedom; AIC, Akaike Information Criterion

\begin{tabular}{|c|c|c|c|c|c|c|}
\hline Factor & Analytical technique & $\begin{array}{l}\text { Unconstrained/ } \\
\text { constrained }\end{array}$ & Model & Df & InLik & AIC \\
\hline \multirow[t]{4}{*}{ Resource specialisation } & \multirow[t]{4}{*}{ MUSSE } & \multirow[t]{2}{*}{ Unconstrained } & Different diversification rates & 10 & -867.57 & 1755.1 \\
\hline & & & Null model & 8 & -878.19 & 1772.4 \\
\hline & & \multirow[t]{2}{*}{ Constrained } & Different diversification rates & 8 & -870.32 & 1756.6 \\
\hline & & & Null model & 6 & -879.35 & 1770.7 \\
\hline \multirow{2}{*}{$\begin{array}{l}\text { Presence in mountainous } \\
\text { regions }\end{array}$} & \multirow[t]{2}{*}{ BiSSE } & \multirow[t]{2}{*}{ Unconstrained } & Different diversification rates & 5 & -832.96 & 1675.9 \\
\hline & & & Null model & 4 & -841.06 & 1690.1 \\
\hline \multirow[t]{4}{*}{ Biogeographic realms } & \multirow[t]{4}{*}{ MUSSE } & \multirow[t]{2}{*}{ Unconstrained } & Different diversification rates & 26 & -763.47 & 1579.0 \\
\hline & & & Null model & 22 & -784.76 & 1613.5 \\
\hline & & \multirow[t]{2}{*}{ Constrained } & Different diversification rates & 16 & -767.13 & 1566.3 \\
\hline & & & Null model & 12 & -788.08 & 1600.2 \\
\hline \multirow[t]{4}{*}{ Locomotion adaptations } & \multirow[t]{4}{*}{ MUSSE } & \multirow[t]{2}{*}{ Unconstrained } & Different diversification rates & 10 & -708.58 & 1437.2 \\
\hline & & & Null model & 8 & -718.73 & 1453.5 \\
\hline & & \multirow[t]{2}{*}{ Constrained } & Different diversification rates & 8 & -708.58 & 1433.2 \\
\hline & & & Null model & 6 & -718.73 & 1449.5 \\
\hline
\end{tabular}

intervals of time (Hernández Fernández \& Vrba 2005). As a result, extreme generalist lineages are expected to show infrequent events of speciation (Simpson 1953, Vrba 1987, Hernández Fernández \& Vrba 2005, Cantalapiedra et al. 2011). However, in Sciuridae, extreme generalists show a wide array of speciation rates (Fig. 1a). This result may reflect the fact that extreme generalist squirrels include lineages with both low and fast diversification rates. Low diversification rates are congruent with the notion of infrequent speciation events due to low incidence of vicariance (Hernández Fernández \& Vrba 2005). On the other hand, extreme generalists may be well suited for occupying newly established biomes, which eventually may become speciation arenas (Dennis et al. 2011).

\section{BiogeOgRAPHIC REALM AND LOCOMOTION MODE}

Lineages inhabiting different biogeographic realms showed different speciation rates (Fig. 1c), a pattern that may be linked to a combination of multiple geographic and historical factors, including biome distribution, topographic heterogeneity, and intercontinental connections. This result agrees with the idea that colonisation of major land masses promoted the diversification of squirrel lineages arriving in new continents (Mercer \& Roth 2003). Our results showed that Nearctic squirrels have the highest diversification rates. We identify several processes that have interplayed to yield this macroevolutionary signal: the expansion of grass-dominated habitats and increase of biome heterogeneity in Miocene times, habitat fragmentation during the glaciation cycles in the Pleistocene, and radiation in mountain ecosystems. A connection between the North American ground squirrels' radiation (led by Marmotini tribe lineages) and several large-scale environmental events in North America has been repeatedly suggested, including the cooling and aridification of terrestrial ecosystems that led to the grasslands expansion during the Miocene (Black 1972, Harrison et al. 2003, Strömberg 2011, Ge et al. 2014, Zelditch et al. 2015, Mclean et al. 2018) and the isolation of desert patches in the southwest (Bell et al. 2010). Moreover, habitat fragmentation during the Pleistocene glacial cycles may have led to more recent speciation episodes (Rubidge et al. 2014, Zelditch et al. 2015). Our analyses of trait evolution correlation showed that the acquisition of terrestrial habits and the colonisation of the Nearctic realm are intimately interwoven (Fig. 2). Therefore, the high speciation rates obtained for terrestrial locomotion and for Nearctic species (Fig. 1b) reflect the same event: the Miocene and posterior Pleistocene evolutionary radiation of North American Marmotini lineages (Black 1972, Sullivan et al. 2014).

The major expansion of open habitats in Miocene times affected not only Nearctic squirrels. The radiation of terrestrial Nearctic lineages continued in the Palaearctic realm as they expanded into Eurasia during the late Miocene and Pleistocene. The moderately high speciation rates recovered by our modelling approach reflects this Palaearctic radiation of squirrels with terrestrial locomotion (Fig. 1c), which generated almost $70 \%$ of the total squirrel diversity in that realm. This pattern, linked to the availability of open habitats in both the Old and New World, resembles the dynamics of other terrestrial 
(a) Biome specialisation

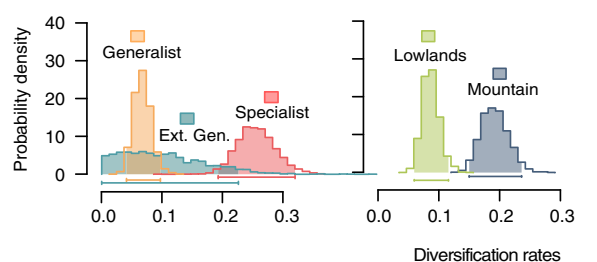

(d)

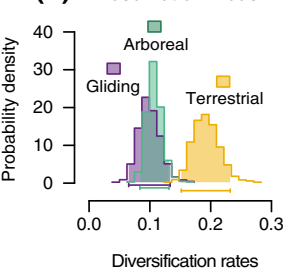

rsification rates c) Biogeographic realms

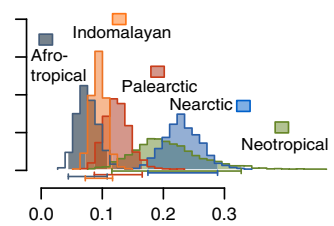

(e)
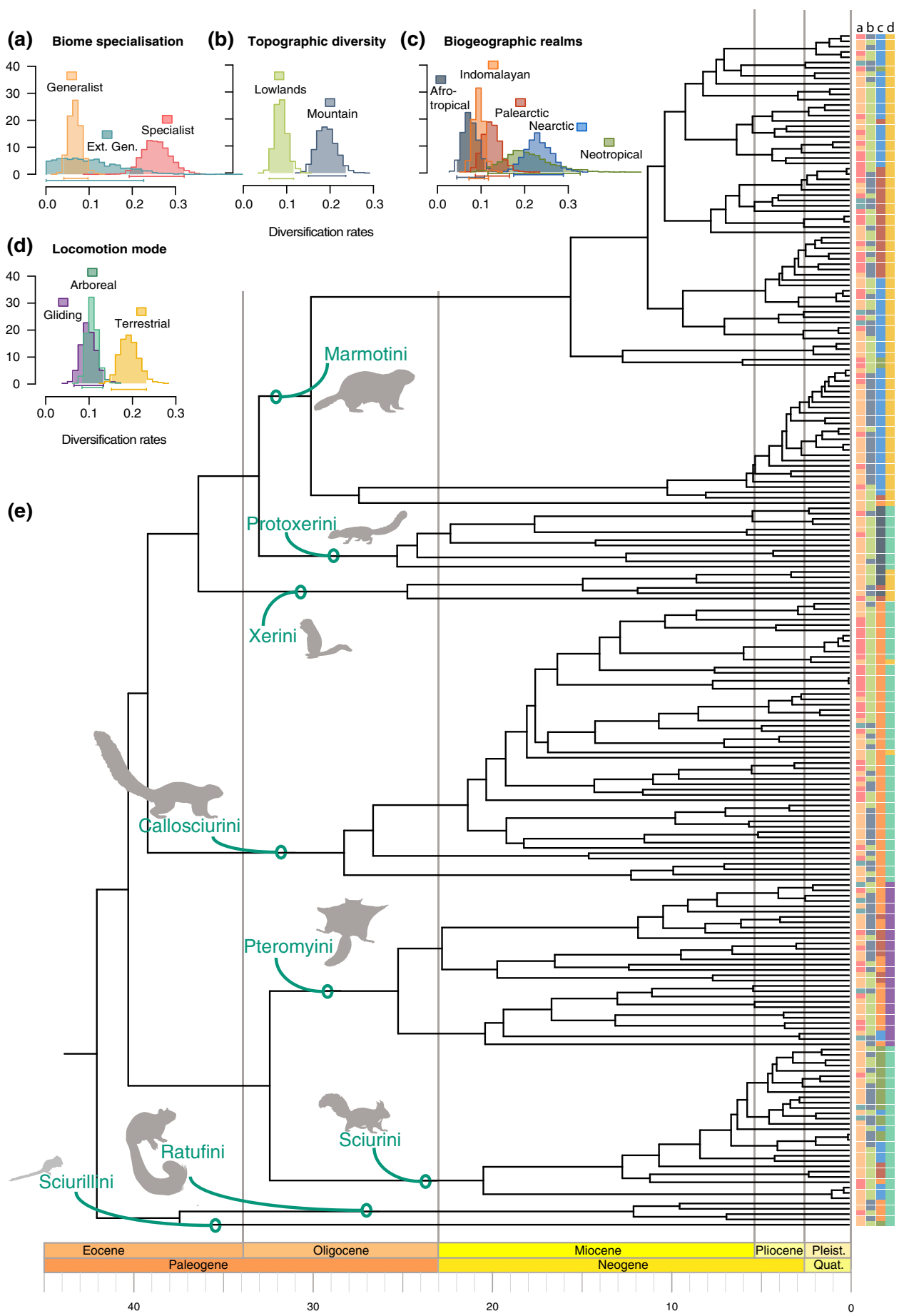

Fig. 1. Distribution of squirrel diversification rates according to the best-fitted state-dependent speciation models for biome specialisation (a), presence in mountainous regions (b), biogeographic realms (c) and locomotion modes (d), and calibrated Bayesian phylogenetic inference for Sciuridae (e). Coloured squares at the tips of the phylogeny represent the different states of each trait. [Colour figure can be viewed at wileyonlinelibrary.com]

mammalian lineages, such as horses (Cantalapiedra et al. 2017). However, the remaining $30 \%$ is formed by markedly slow diversifiers (long branches), such as Atlantoxerus and Spermophilopsis, which contributed to the moderate speciation rate for the whole Palaearctic dataset. Other factors may explain the differences between Palaearctic and Nearctic rates. The larger extension of biomes in the Palaearctic (a result of the longitudinal extension of 


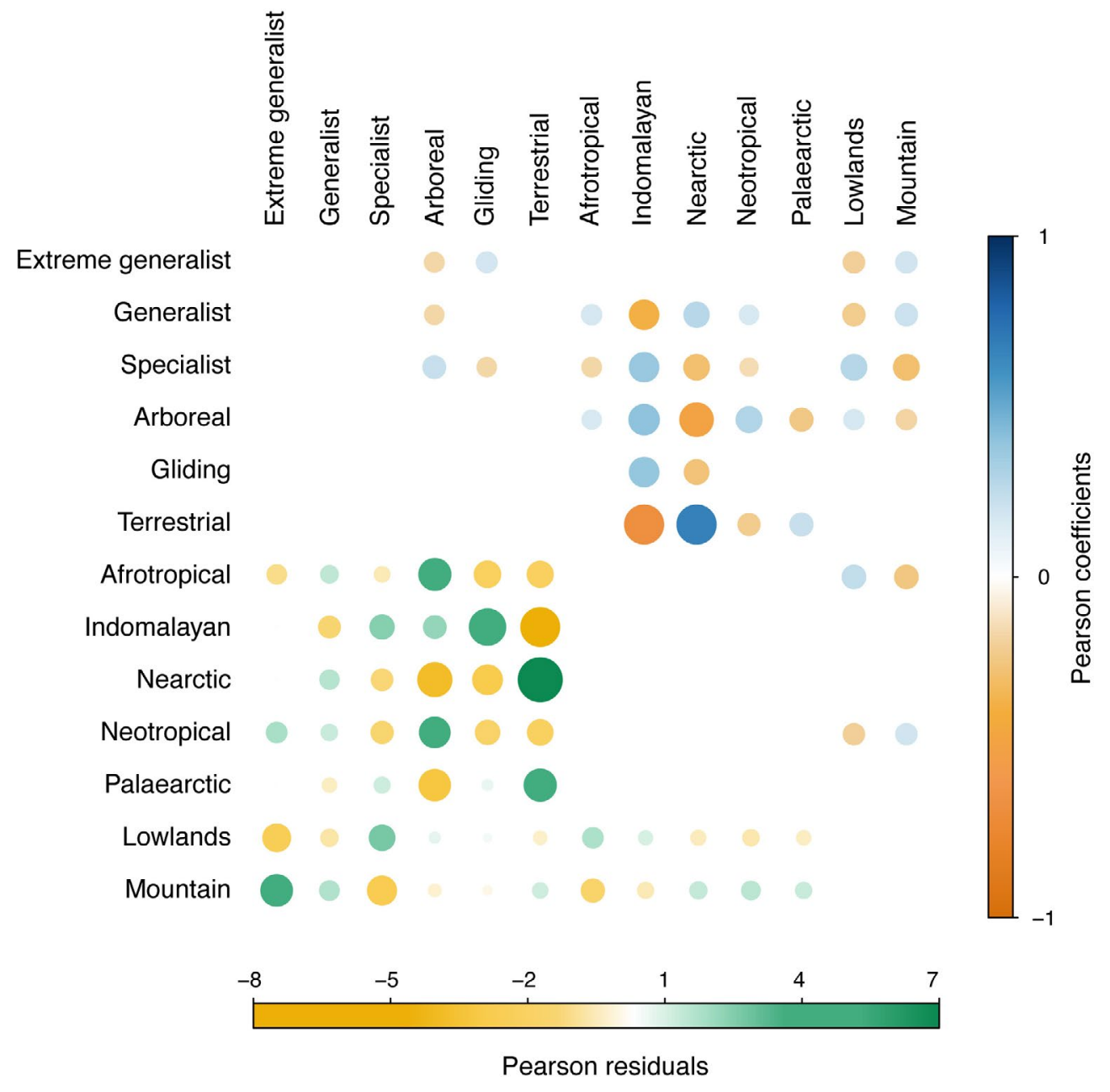

Fig. 2. Trait evolution correlation in squirrels. Contingency matrix resulting from the chi-squared test of independence (below the diagonal; the scale represents the gradient for Pearson residuals and shows positive and negative values) and correlation coefficients between states in each node of the phylogeny (above the diagonal; the scale represents the gradient for Pearson coefficient values and shows positive and negative values). The size of the dot in each cell reflects the relative magnitude of the correlation. Dots are only displayed for statistically significant analyses. [Colour figure can be viewed at wileyonlinelibrary.com]

Eurasia) has generated a more homogenous biogeographic realm than in the Nearctic, explaining the lower diversification rates of squirrels inhabiting the Palaearctic realm. Also, the east-west orientation of Palearctic mountain ranges may contribute to the lower speciation rates in this realm, since mountain ranges may represent a barrier to latitudinal shifts in species' ranges during climatic disturbance events. This could have increased extinctions in the Palaearctic realm, minimising the number of species surviving past speciation events and, therefore, yielding underestimated speciation rates. This has been previously proposed as a factor driving differential extinctions between North America and Europe during the Pleistocene glaciations (Brown 1995), as well as an explanation for the higher tree diversity in eastern North America than in Europe (MacArthur 1972).
Old World tropical realms - Afrotropical and Indomalayan - showed the lowest speciation rates (Fig. 1c). Squirrels have occupied the Indomalayan realm since early stages in their evolutionary history and are highly diverse in this realm, which harbours $40 \%$ of all squirrel species (Koprowski et al. 2016). Thus, the species richness in this realm is likely to be the result of an accumulation of species over long geological time-scales rather than fast species diversification, a pattern observed in other vertebrate groups (Rabosky et al. 2018). This is also supported by the deep divergences recovered for South-East Asian squirrels, probably as a consequence of recurrent speciation events promoted by sea-level fluctuations from the Miocene onwards (Mercer \& Roth 2003, den Tex et al. 2010, Hawkins et al. 2016). On the other hand, despite having been occupied by squirrels for the last 25 million 
years, the Afrotropical realm harbours just $12 \%$ of today's species richness (Appendix S5), which is congruent with the low speciation recovered by our phylogenetic approach (Fig. 1c). Since this pattern is not replicated in the Neotropics, where a recent radiation has been observed (Roth \& Mercer 2008, Zelditch et al. 2015), it appears that the mechanisms regulating species diversity in Paleotropical species pools are not applicable to all tropical realms. In the Afrotropical and Indomalayan realms, we may be recovering the signal of ecological saturation dynamics of older species pools (Marshall \& Quental 2016). Alternatively, the squirrel radiation in the Neotropics may be too recent for extinctions to be observed, as suggested by Roth and Mercer (2008). The lower representation of Indomalayan (69\%, Appendix S5) and Afrotropical species (46\%, Appendix S5) in the phylogeny may also have produced artificially low speciation rates for these realms in the biogeographic analysis.

\section{OCCUPANCY OF MOUNTAIN RANGES}

Overall, Sciuridae lineages associated with mountain ranges showed significantly higher speciation rates than those in lowlands (Fig. 1b), suggesting that the occupancy of mountain ranges promotes speciation. This supports, at least for these clades, the idea that the higher species richness found in most mountainous areas than in surrounding lowland areas (Hawkins et al. 2012, Fjeldså et al. 2012) is mostly due to high diversification rates ('cradle hypothesis'), and, to a lesser extent, to the accumulation of species with little extinction ('museum hypothesis'). A large body of evidence has linked mountainous regions with high speciation rates. The elevational gradient and the topographic heterogeneity, in combination with shifting climate, generate physiographic and climatic barriers in mountainous regions that produce resource fragmentation, promoting isolation and subsequent allopatric speciation (Vrba 1992, Badgley 2010). Other researchers have suggested the occupancy of mountainous habitats as a major driver of speciation in squirrels (Oshida et al. 2004, Arbogast 2007, Villalobos \& Cervantes-Reza 2007, Li et al. 2008, Rubidge et al. 2014, Pečnerová et al. 2015), rodents (Badgley et al. 2017), and mammals in general (Davis et al. 2008), as well as in other organisms such as plants (Lagomarsino et al. 2016), reptiles (Garcia-Porta et al. 2017), and birds (Beckman \& Witt 2015). The relationships observed between states in different traits (Fig. 2) indicate that most extreme generalist species inhabit mountainous regions (all but Petaurista philippensis). This is probably due to their versatility: they can occupy different biomes, which allow them to have a broader elevational range. Conversely, biome specialists are more likely to be associated with lowlands (88 species). Relatively few biome specialist species occur in mountainous areas (21 species); of these, $76 \%$ are present in the Holarctic, mostly in high-elevation vegetation belts (analogous to steppe or tundra biomes). This is congruent with a Pleistocene diversification of mountain species due to the alternation of glacial and interglacial episodes (Arbogast 2007, Rubidge et al. 2014). A substantial part of the North American squirrel radiation occurred in mountain-associated habitats, which hold over two thirds of the squirrel species in North America (Badgley 2010).

Our findings show that the radiation of squirrels into Nearctic mountainous habitats probably kept fuelling the already successful radiation of terrestrial lineages during the Miocene and that Pleistocene glaciation cycles reinforced this pattern. Additionally, the rapid radiation of squirrels in South America (Roth \& Mercer 2008, Pečnerová et al. 2015, Zelditch et al. 2015) could be associated with the topographic complexity of the mountain ranges in Central America and the Andes. This complexity may have contributed to the high speciation rates observed in the Neotropical realm, which are mostly associated with the cloud forest vegetation belts at middle-mountain elevations. In contrast, the occupancy of mountain ranges in the Indomalayan region seems to be ancient and is not related to high speciation rates (den Tex et al. 2010, Hawkins et al. 2016). In this case, the higher diversification rates proposed for lowland species might reflect the enhancing effect of sea-level fluctuations on species origination (Mercer \& Roth 2003).

\section{Ecological and biogeographic evolution of squirrels}

We reconstructed ancestral states for all the traits included in this analysis (Appendices S15-S18). We observed two main waves of biome-specialisation events (Fig. 3): one during the Miocene (around 20-15 Ma), and another in the Plio-Pleistocene (around $5 \mathrm{Ma}$ ). We used an isotope-based paleoclimate curve (Zachos et al. 2001) to provide a broad-scale environmental frame for these two events (Fig. 3). The first wave occurred within the tribe Callosciurini (southern Asian tree squirrels), coincident with a peak of temperatures during the Miocene Climatic Optimum (15 Ma), and gave rise to lineages specialised in warm and arboreal biomes (mostly equatorial rainforest and deciduous woodland; Fig. 3). The second biomespecialisation wave took place during the cooling trend that started after the development of the East Antarctic ice sheet around $14 \mathrm{Ma}$ (Flower \& Kennett 1994). Most of the specialisation events of the second wave appeared to be concentrated in the Plio-Pleistocene (the last five million years); they were particularly widespread in the Marmotini tribe, where many lineages specialised in the steppe biome (Fig. 3). This suggests that warmer, less 


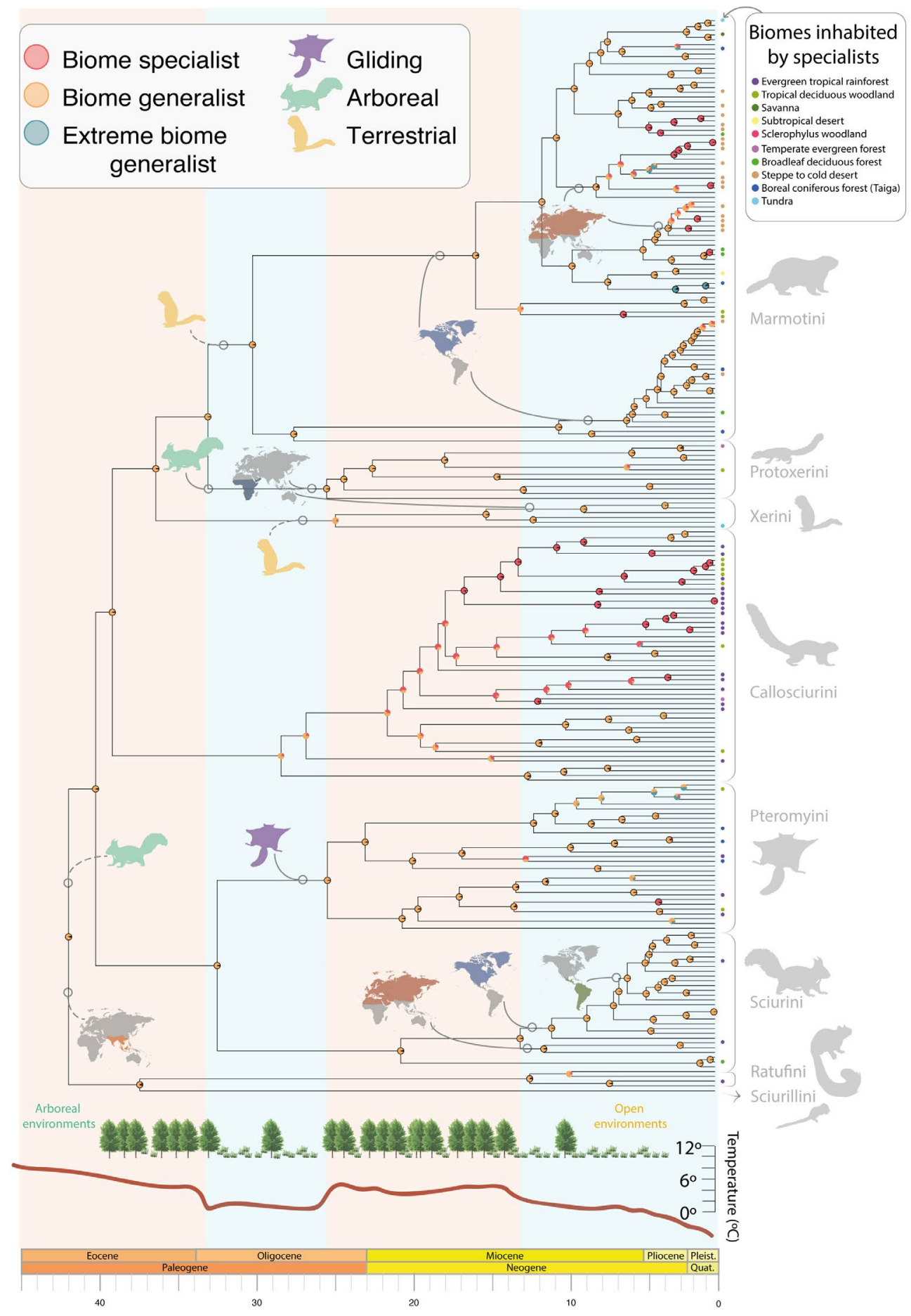

Fig. 3. Ancestral reconstruction of the degree of biome specialisation in squirrels. Nodes with significant trait proportions are outlined in black. Biome occupation for specialist species is presented at the tips of the phylogeny. The most remarkable biogeographic dispersals, based on the biogeographic realm ancestral reconstruction (Appendix S17), are represented in the phylogeny branches, as are changes in locomotion mode (Appendix S18). Significant biogeographic dispersals and locomotion mode changes are shown by solid lines; statistically non-significant ones are shown by dashed lines. Long-term warm and cold intervals, indicated as the background colour and in the graph (bottom), are based on the temperature curve of Zachos et al. (2001), considering the threshold $3^{\circ} \mathrm{C}$. Arboreal and open environments (bottom) reflect environmental changes. [Colour figure can be viewed at wileyonlinelibrary.com] 
arid conditions (see Fig. 3) were associated with specialisation of species in warm biomes (tropical rainforest and tropical deciduous woodlands), while colder conditions (see Fig. 3) favoured species specialising in cold biomes (mainly steppes). Within the context of this longterm climatic trend, subsequent proliferation of bioclimatically specialised lineages was probably induced by the relatively rapid climatic fluctuations produced by cyclic orbital alterations (Milankovitch cycles) that marked the Cenozoic (Berger 1988). According to the habitat theory, these short-term perturbations would have brought about substantial fragmentation of predominant biome patches and enhanced the vicariance of biome-restricted taxa (Vrba 1999).

Our ancestral reconstruction does not resolve whether the acquisition of a terrestrial locomotion mode occurred once (with a subsequent regression to arboreality in the Protoxerini tribe) or twice, a question that has been addressed (Steppan et al. 2004, Roth 2005) but has still not been answered. Our results show that terrestrial locomotion was already widespread in the middle Miocene (Fig. 3; Appendix S18), which is congruent with the hypothesis that relates the higher speciation rates found in terrestrial squirrel species (Fig. 1d) with the expansion of modern grassland ecosystems during the Miocene (Harrison et al. 2003, Ge et al. 2014, Zelditch et al. 2015). Most of these species are included in the tribe Marmotini, which diversified during the transition between the middle and the late Miocene (Fig. 3), possibly as a response to the appearance of this new type of ecosystem that offered new ecological opportunities for evolutionary radiation (Van Valen 1971, Cantalapiedra et al. 2017). After the colonisation of such new environments, subsequent contraction and fragmentation during intervals of climatic change associated with the Milankovitch cycles could have led to increased speciation rates. On the other hand, the initial cladogenesis of the arboreal and gliding species of southern Asia and Africa seems to be related to the early Miocene warm interval, while arboreal species in the Holarctic and Neotropic realms diversified in the colder Plio-Pleistocene (Fig. 3).

Although the reconstruction in the basal node is not robust, our phylogenetic modelling reconstructs an Indomalayan origin for Sciuridae (Appendix S17). This model suggests early dispersal of Sciurillus into South America, probably from Indomalayan ancestors, which could be parallel to the dispersal of some hystricomorph rodent groups that, from Asian ancestors, dispersed into Africa and eventually South America during the Eocene (Huchon \& Douzery 2001, Antoine et al. 2012, Voloch et al. 2013, Sallam \& Seiffert 2016). Based on our reconstruction, an Oligocene dispersal into the Afrotropical realm gave rise to the Protoxerini, possibly associated with the dispersal of anthropoid primates into Africa (Seiffert 2006). Nevertheless, due to limited sampling of African fossils in rainforest areas, the first fossils assigned to this tribe are not found until the upper Miocene of Kenya (Kubwaxerus; Cifelli et al. 1986). The African ground squirrels, tribe Xerini, appear to have occupied this realm during the early Miocene, in association with the development of the Gomphotherium bridge between Asia and Africa (Van der Made 1999). This is congruent with the fossil record of the tribe, which is found from the late Oligocene in Europe and is especially abundant in Spain and North Africa in the Miocene (Black 1972). Our reconstruction shows that an early dispersal of Marmotini ancestors into the Palaearctic during the Eocene or Oligocene was probable, although not statistically significant, which is consistent with the European fossil record of Palaeosciurus (Vianey-Liaud 1974). Although it is not statistically significant, the presence of the Sciurini in the Palaearctic could be traced back to the early Miocene. In our reconstruction, several Pteromyini lineages dispersed into the Palaearctic from the Indomalayan realm during the late Miocene, although there is fossil evidence that some other lineages of this tribe were present in Europe from the Oligocene onwards (Heissig 1979a,1979b, De Bruijn 1999, Dawson 2003, Heissig 2003, Gómez Cano et al. 2014, Casanovas-Vilar et al. 2018). In fact, other research has suggested a Palearctic origin of Pteromyini ( $L u$ et al. 2013). Dispersal of Marmotini into the Nearctic took place during the early Miocene (probably in two different lineages), and its diversification in this realm preceded two dispersal events back to the Palaearctic in the late Miocene (Spermophilus) and Pliocene (Marmota). The arrivals of Sciurus in the late Miocene and Glaucomys in the Pliocene completed the Nearctic faunal association and preceded the latest Miocene development of the Neotropical Sciurus lineage (Oshida \& Masuda 2000, Pečnerová \& Martínková 2012).

The ancestral reconstruction suggests that mountain ranges were inhabited fairly late in squirrels' evolutionary history (Appendix S16), mostly during the late Miocene and the Pliocene (the last 12 million years), in association with the late development of the Alpine Orogeny. This process took place as several independent events in the genus Ratufa, some Neotropical Sciurini, Palaearctic Pteromyini, Petaurista, several basal lineages of Callosciurini and multiple Marmotini lineages. The Indomalayan lineages may have been induced to occupy mountain ranges by the elevation of the sea level (Mercer \& Roth 2003, den Tex et al. 2010, Hawkins et al. 2016), while for Holarctic species, mountains may have constituted glacial refugia (Arbogast 2007, Li et al. 2008, Rubidge et al. 2014). 


\section{CONCLUSION: A MULTI-FACTOR SCENARIO FOR THE MACROEVOLUTION OF SCIURIDAE}

Diversification rates of squirrel lineages have been affected by the interplay of several drivers. In particular, lineages restricted to a single biome (biome specialists) showed higher diversification rates than any other fast-diversifying group (Nearctic, mountainous, or terrestrial species; see Fig. 1). This suggests that, although all of the factors we considered (biogeographic realm, occupying mountainous regions and locomotion mode) have a significant role in the macroevolutionary history of squirrels, biome specialisation is the one key feature with the highest impact on diversification rates throughout the whole phylogeny of Sciuridae.

Our results support the notion of a fundamental role of abiotic factors - climatic forcing and tectonic events - in the unfolding of macroevolutionary patterns (Vrba 1992, Badgley 2010, Gómez Cano et al. 2013, Cantalapiedra et al. 2017). Nevertheless, the development of some intrinsic characteristics, such as new locomotion adaptations, would have allowed certain lineages to cope with the shifting abiotic settings, propelling their speciation (e.g. Gómez Cano et al. 2013, Cantalapiedra et al. 2014a).

The alternation of cold and warm intervals during the Cenozoic may have been responsible for the differential diversification of squirrels during their evolutionary history. This validates the idea that both global warming and global cooling may lead to increased diversification rates (Vrba 1995). Long-term cold intervals ('icehouse intervals') may have favoured the dispersal and geographic expansion of species with a certain array of ecological traits (e.g. terrestrial locomotion). Short-term warming events (associated with the Milankovitch cyclicity) during these cold intervals could be responsible for the proliferation of lineages specialised in cold biomes (Vrba 1995), due to the subsequent contraction and fragmentation of at least some of the new habitats that originated during the longer term (particularly, steppe). Such short-term warm intervals would also account for the high diversification rates attained by mountain squirrel lineages, due to elevational shifts in their geographic ranges and the associated vicariance of their populations (Badgley 2010). On the contrary, long-term warm intervals ('greenhouse intervals') favoured the geographic expansion of species with alternative ecological traits (e.g. arboreal and gliding locomotion modes), while short-term cooling events during these intervals promoted the proliferation of different biome specialist lineages (e.g. rainforest species).
These findings are congruent with the idea that the shifting of abiotic settings over time would affect diversification rates differently in lineages with different ecological affinities (Vrba 1992). Although the general temperature trend during the Cenozoic marked the longterm greenhouse and icehouse intervals, the Milankovitch cycles were the main drivers for the short-term climatic cyclicity responsible for the diversification of biome specialists and mountain lineages.

In the light of these conclusions, we expect a severe impact on speciation and extinction rates if the current trend of anthropogenic climate change is maintained. We expect the extinction of around $16 \%$ of squirrel species, with especially high rates in South America and African arboreal squirrels (Sciurini and Protoxerini), due to habitat loss caused by the current trends in global warming and deforestation (Strassburg et al. 2012, Urban 2015). Additionally, we expect high extinction rates in Callosciurini and Pteromiyini tribes, as they have a higher percentage of specialist species (Gómez Cano et al. 2013). Furthermore, the surviving species are likely to undergo a reduction of their geographic ranges and abundance. As a result, diversity of Sciuridae, a widespread family currently found in a wide array of environments, could be substantially reduced. This highlights the urgency of taking immediate action to mitigate the accelerating global warming.

\section{ACKNOWLEDGEMENTS}

We are grateful to the Carranza Lab, especially to Salvador Carranza, Marc Simó-Riudalbas, and Héctor TejeroCicuéndez, for the help provided with the phylogenetic analyses. We thank Miriam L. Zelditch and Donald L. Swiderski for valuable comments on the phylogeny. Francisco J. Serrano, Guillermo Navalón, Fernando Blanco, and Gabriel Arellano provided helpful comments at early stages of this paper. We are grateful to Emiliano Mori and an anonymous referee for their valuable comments and suggestions, which helped to improve the original manuscript. We also want to thank the editors Nancy Jennings and Danilo Russo, as well as Violeta Menéndez González for proofreading. This is a contribution of the PMMV team of the Complutense University of Madrid, as part of the Research Group UCM 910607 on Evolution of Cenozoic Mammals and Continental Palaeoenvironments. I.M. was funded by a predoctoral grant from the Complutense University of Madrid (CT27/16-CT28/16). J.L.C was funded by the Talent Attraction Program of the Madrid Government and the Universidad de Alcalá (2017-T1/AMB5298). This work was partially supported by projects PGC2018-094955-A-I00 and PGC2018-094122-B-I00 funded by: FEDER/ Ministerio de Ciencia, Innovación y Universidades-Agencia Estatal de Investigación. 


\section{REFERENCES}

Ancillotto L, Mori E (2017) Adaptive significance of coat colouration and patterns of Sciuromorpha (Rodentia). Ethology, Ecology and Evolution 29: 241-254.

Antoine PO, Marivaux L, Croft DA, Billet G, Ganerod M, Jaramillo C et al. (2012) Middle Eocene rodents from Peruvian Amazonia reveal the pattern and timing of caviomorph origins and biogeography. Proceedings of the Royal Society B: Biological Sciences 279: 1319-1326.

Arbogast BS (2007) A brief history of the New World flying squirrels: phylogeny, biogeography, and conservation genetics. Journal of Mammalogy 88: 840-849.

Badgley C (2010) Tectonics, topography, and mammalian diversity. Ecography 33: 220-231.

Badgley C, Smiley TM, Terry R, Davis EB, DeSantis LRG, Fox DL et al. (2017) Biodiversity and topographic complexity: modern and geohistorical perspectives. Trends in Ecology and Evolution 32: 211-226.

Beckman EJ, Witt CC (2015) Phylogeny and biogeography of the New World siskins and goldfinches: rapid, recent diversification in the Central Andes. Molecular Phylogenetics and Evolution 87: 28-45.

Bell KC, Hafner DJ, Leitner P, Matocq MD (2010) Phylogeography of the ground squirrel subgenus Xerospermophilus and assembly of the Mojave Desert biota. Journal of Biogeography 37: 363-378.

Benton MJ (2009) The red queen and the court jester: character displacement and abiotic factors through time. Science 323: 728-732.

Berger A (1988) Milankovitch theory and climate. Reviews of Geophysics 26: 624-657.

Black CC (1972) Holarctic evolution and dispersal of squirrels (Rodentia: Sciuridae). In: Dobzhansky T, Hecht MK, Steere WC (eds) Evolutionary Biology, 305-322. Springer, New York, New York, USA.

Brown JH (1995) Macroecology. University of Chicago Press, Chicago, Illinois, USA.

Cantalapiedra JL, Hernández Fernández M, Morales J (2011) Biomic specialization and speciation rates in ruminants (Cetartiodactyla, Mammalia): a test of the resource-use hypothesis at the global scale. PLoS One 6: e28749.

Cantalapiedra JL, FitzJohn RG, Kuhn TS, Hernández Fernández M, DeMiguel D, Azanza B, Morales J, Mooers AO (2014a) Dietary innovations spurred the diversification of ruminants during the Caenozoic. Proceedings of the Royal Society B: Biological Sciences 281: 20132746.

Cantalapiedra JL, Hernández Fernández M, Morales J (2014b) The biogeographic history of ruminant faunas determines the phylogenetic structure of their assemblages at different scales. Ecography 37: 1-9.
Cantalapiedra JL, Prado JL, Hernández Fernández M, Alberdi MT (2017) Decoupled ecomorphological evolution and diversification in Neogene-Quaternary horses. Science 355: 627-630.

Casanovas-Vilar I, Garcia-Porta J, Fortuny J, Sanisidro Ó, Prieto J, Querejeta M et al. (2018) Oldest skeleton of a fossil flying squirrel casts new light on the phylogeny of the group. eLife 7: e39270.

Cifelli RL, Ibui AK, Jacobs LL, Thorington RW Jr (1986) A giant tree squirrel from the late Miocene of Kenya. Journal of Mammalogy 67: 274-283.

Davis EB, Koo MS, Conroy C, Patton JL, Moritz C (2008) The California Hotspots Project: identifying regions of rapid diversification of mammals. Molecular Ecology 17: 120-138.

Dawson MR (2003) Paleogene rodents of Eurasia. Deinsea 10: 97-126.

De Bruijn HD (1999) Superfamily Sciuroidea. In: Rössner GE, Heissig K (eds) The Miocene Land Mammals of Europe, 271-280. Verlag Dr. Friedrich Pfeil, München, Germany.

Den Tex R-J, Thorington RW, Maldonado JE, Leonard JA (2010) Speciation dynamics in the SE Asian tropics: putting a time perspective on the phylogeny and biogeography of Sundaland tree squirrels, Sundasciurus. Molecular Phylogenetics and Evolution 55: 711-720.

Dennis RLH, Dapporto L, Fattorini S, Cook LM (2011) The generalism-specialism debate: the role of generalists in the life and death of species. Biological Journal of the Linnean Society 104: 725-737.

Drummond A, Rambaut A (2007) BEAST: Bayesian evolutionary analysis by sampling trees. BMC Evolutionary Biology 7: 214.

Emry RJ, Thorington RW (1982) Descriptive and comparative osteology of the oldest fossil squirrel, Protosciurus (Rodentia: Sciuridae). Smithsonian Contributions to Paleobiology 47: 1-35.

Fabre P-H, Hautier L, Dimitrov D, Douzery EJP (2012) A glimpse on the pattern of rodent diversification: a phylogenetic approach. BMC Evolutionary Biology 12: 88.

Feldman A, Sabath N, Pyron RA, Mayrose I, Meiri S (2016) Body sizes and diversification rates of lizards, snakes, amphisbaenians and the tuatara. Global Ecology and Biogeography 25: 187-197.

Finarelli JA, Badgley C (2010) Diversity dynamics of Miocene mammals in relation to the history of tectonism and climate. Proceedings of the Royal Society B: Biological Sciences 277: 2721-2726.

FitzJohn RG (2012) Diversitree: comparative phylogenetic analyses of diversification in R. Methods in Ecology and Evolution 3: 1084-1092.

Fjeldså J, Bowie RCK, Rahbek C (2012) The role of mountain ranges in the diversification of birds. Annual 
Review of Ecology, Evolution, and Systematics 43: 249-265.

Flower BP, Kennett JP (1994) The middle Miocene climatic transition: east Antarctic ice sheet development, deep ocean circulation and global carbon cycling. Palaeogeography, Palaeoclimatology, Palaeoecology 108: 537-555.

Fritz SA, Schnitzler J, Eronen JT, Hof C, Böhning-Gaese K, Graham CH (2013) Diversity in time and space: wanted dead and alive. Trends in Ecology \& Evolution 28: 509-516.

Garcia-Porta J, Simó-Riudalbas M, Robinson M, Carranza S (2017) Diversification in arid mountains: biogeography and cryptic diversity of Pristurus rupestris rupestris in Arabia. Journal of Biogeography 44: 1694-1704.

Ge DY, Liu X, Lv XF, Zhang ZQ, Xia L, Yang QS (2014) Historical biogeography and body form evolution of ground squirrels (Sciuridae: Xerinae). Evolutionary Biology 41: 99-114.

Gómez Cano AR, Cantalapiedra JL, Mesa A, Moreno Bofarull A, Hernández Fernández M (2013) Global climate changes drive ecological specialization of mammal faunas: trends in rodent assemblages from the Iberian Plio-Pleistocene. BMC Evolutionary Biology 13: 94.

Gómez Cano AR, Cantalapiedra JL, Álvarez-Sierra MÁ, Hernández Fernández M (2014) A macroecological glance at the structure of late Miocene rodent assemblages from southwest Europe. Scientific Reports 4: 6557.

Haile-Selassie Y, Woldegabriel G, White TD, Bernor RL, Degusta D, Renne PR et al. (2004) Mio-Pliocene mammals from the Middle Awash, Ethiopia. Geobios 37: 536-552.

Harrison RG, Bogdanowicz SM, Hoffmann RS, Yensen E, Sherman PW (2003) Phylogeny and evolutionary history of the ground squirrels (Rodentia: Marmotinae). Journal of Mammalian Evolution 10: 249-276.

Hawkins BA, McCain CM, Davies TJ, Buckley LB, Anacker BL, Cornell HV et al. (2012) Different evolutionary histories underlie congruent species richness gradients of birds and mammals. Journal of Biogeography 39: 825-841. Hawkins MTR, Helgen KM, Maldonado JE, Rockwood LL, Tsuchiya MTN, Leonard JA (2016) Phylogeny, biogeography and systematic revision of plain long-nosed squirrels (genus Dremomys, Nannosciurinae). Molecular Phylogenetics and Evolution 94: 752-764.

Heissig K (1979a) Die frühesten Flughörnchen und primitiven Ailuravinae (Rodentia, Mamm.) aus dem süddeutschen Oligozän. Mitteilungen der Bayerischen Staatssammlung für Paläontologie und historisches Geologie 19: 139-169.

Heissig K (1979b) Die hypothetische Rolle Südost- europas bei den Säugetierwanderungen im Eozän und Oligozän. Neues Jahrbuch für Geologie und Paläontologie Monatshefte 2: 83-96.
Heissig K (2003) Origin and early dispersal of the squirrels and their relatives. Deinsea 10: 277-286.

Hernández Fernández M (2001) Bioclimatic discriminant capacity of terrestrial mammal faunas. Global Ecology \& Biogeography 10: 189-204.

Hernández Fernández M, Vrba ES (2005) Macroevolutionary processes and biomic specialization: testing the resourceuse hypothesis. Evolutionary Ecology 19: 199-219.

Huchon D, Douzery EJP (2001) From the Old World to the New World: a molecular chronicle of the phylogeny and biogeography of hystricognath rodents. Molecular Phylogenetics and Evolution 20: 238-251.

IUCN (2020) The IUCN Red List of Threatened Species. Version 2020-1. https://www.iucnredlist.org.

Jablonski D (2008) Species selection: theory and data. Annual Review of Ecology, Evolution, and Systematics 39: 501-524.

Jetz W, McPherson JM, Guralnick RP (2012) Integrating biodiversity distribution knowledge: toward a global map of life. Trends in Ecology \& Evolution 27: 151-159.

Katoh K, Toh H (2008) Recent developments in the MAFFT multiple sequence alignment program. Briefings in Bioinformatics 9: 286-298.

Kearse, M, Moir, R, Wilson, A, Stones-Havas, S, Cheung, M, Sturrock, S et al. (2012) Geneious Basic: an integrated and extendable desktop software platform for the organization and analysis of sequence data. Bioinformatics 28: $1647-1649$.

Koprowski J, Goldstein E, Bennett K, Pereira C (2016) Family Sciuridae. In: Wilson DE, Lacher TE, Mittermeier RA (eds) Handbook of the Mammals of the World, Volume 6. Lagomorphs and Rodents, 648-987. Lynx Edicions, Barcelona, Spain.

Lagomarsino LP, Condamine FL, Antonelli A, Mulch A, Davis CC (2016) The abiotic and biotic drivers of rapid diversification in Andean bellflowers (Campanulaceae). New Phytologist 210: 1430-1442.

Lanfear R, Calcott B, Ho SYW, Guindon S (2012) PartitionFinder: combined selection of partitioning schemes and substitution models for phylogenetic analyses. Molecular Biology and Evolution 29: 1695-1701.

Li S, Yu F, Yang S, Wang Y, Jiang X, McGuire PM, Feng Q, Yang J (2008) Molecular phylogeny of five species of Dremomys (Rodentia: Sciuridae), inferred from cytochrome $b$ gene sequences. Zoologica Scripta 37: 349-354.

Lu X, Ge D, Xia L, Zhang Z, Li S, Yang Q (2013) The evolution and paleobiogeography of flying squirrels (Sciuridae, Pteromyini) in response to global environmental change. Evolutionary Biology 40: 117-132.

MacArthur RH (1972) Geographical Ecology: Patterns in the Distribution of Species. Princetown University Press, Princetown, New Jersey, USA. 
Maddison WP, Midford PE, Otto SP (2007) Estimating a binary character's effect on speciation and extinction. Systematic Biology 56: 701-710.

Marshall CR, Quental TB (2016) The uncertain role of diversity dependence in species diversification and the need to incorporate time-varying carrying capacities. Philosophical Transactions of the Royal Society B: Biological Sciences 371: 20150217.

Mclean BS, Bell KC, Allen JM, Helgen KM, Cook JA (2018) Impacts of inference method and data set filtering on phylogenomic resolution in a rapid radiation of ground squirrels (Xerinae: Marmotini). Systematic Biology 68: 298-316.

Mendes CP, Koprowski JL, Galetti M (2019) NEOSQUIRREL: a data set of ecological knowledge on Neotropical squirrels. Mammal Review 49: 210-225.

Mercer JM, Roth VL (2003) The effects of Cenozoic global change on squirrel phylogeny. Science 299: 1568-1572.

Miller MA, Pfeiffer W, Schwartz T (2010) Creating the CIPRES Science Gateway for inference of large phylogenetic trees. Gateway Computing Environments Workshop (GCE) 2010: 1-8.

Moreno Bofarull A, Arias Royo A, Hernández Fernández M, Ortiz-Jaureguizar E, Morales J (2008) Influence of continental history on the ecological specialization and macroevolutionary processes in the mammalian assemblage of South America: differences between small and large mammals. BMC Evolutionary Biology 8: 97.

Mori E, Milanesi P, Menchetti M, Zozzoli R, Monaco A, Capizzi D, Nerva L (2018) Genetics reveals that freeranging chipmunks introduced to Italy have multiple origins. Hystrix 29: 239-242.

Oshida T, Masuda R (2000) Phylogeny and zoogeography of six squirrel species of the genus Sciurus (Mammalia, Rodentia), inferred from Cytochrome b gene sequences. Zoological Science 17: 405-409.

Oshida T, Shafique CM, Barkati S, Yasuda M, Nor Azman H, Hideki E, Hisashi Y, Masuda R (2004) Phylogenetic position of the small Kashmir flying squirrel, Hylopetes fimbriatus ( $\asymp$ Eoglaucomys fimbriatus), in the subfamily Pteromyinae. Canadian Journal of Zoology 82: 1336-1342.

Parham JF, Donoghue PCJ, Bell CJ, Calway TD, Head JJ, Holroyd PA et al. (2012) Best practices for justifying fossil calibrations. Systematic Biology 61: 346-359.

Pečnerová P, Martínková N (2012) Evolutionary history of tree squirrels (Rodentia, Sciurini) based on multilocus phylogeny reconstruction. Zoologica Scripta 41: 211-219.

Pečnerová P, Moravec JC, Martínková N (2015) A skull might lie: modeling ancestral ranges and diet from genes and shape of tree squirrels. Systematic Biology 64: 1074-1088.

R Core Team (2008) R: a Language and environment for Statistical Computing. R Foundation for Statistical Computing, Vienna, Austria.
Rabosky DL, Slater GJ, Alfaro ME (2012) Clade age and species richness are decoupled across the eukaryotic tree of life. PLoS Biology 10: e1001381.

Rabosky DL, Chang J, Title PO, Cowman PF, Sallan L, Friedman $\mathrm{M}$ et al. (2018) An inverse latitudinal gradient in speciation rate for marine fishes. Nature 559: 392-395.

Rambaut A, Drummond AJ, Suchard M (2014) Tracer v1.6. http://beast.bio.ed.ac.uk.

Roth L (2005) Variation and versatility in macroevolution. In: Hallgrímsson B, Hall BK (eds) Variation, 455-474. Elsevier, Netherlands.

Roth VL, Mercer JM (2008) Differing rates of macroevolutionary diversification in arboreal squirrels. Current Science 95: 857-861.

Rubidge EM, Patton JL, Moritz C (2014) Diversification of the alpine chipmunk, Tamias alpinus, an alpine endemic of the Sierra Nevada, California. BMC Evolutionary Biology 14: 34.

Sallam HM, Seiffert ER (2016) New phiomorph rodents from the latest Eocene of Egypt, and the impact of Bayesian "clock"-based phylogenetic methods on estimates of basal hystricognath relationships and biochronology. PeerJ 4: e1717.

Sauquet H, Ho SYW, Gandolfo MA, Jordan GJ, Wilf P, Cantrill DJ et al. (2012) Testing the impact of calibration on molecular divergencetimes using a fossil-rich group: the case of Nothofagus (Fagales). Systematic Biology 61: 289-313.

Seiffert ER (2006) Revised age estimates for the later Paleogene mammal faunas of Egypt and Oman. PNAS 103: 5000-5005.

Silvestro D, Michalak I (2012) raxmlGUI: a graphical front-end for RAxML. Organisms Diversity \& Evolution 12: 335-337.

Silvestro D, Antonelli A, Salamin N, Quental TB (2015) The role of clade competition in the diversification of North American canids. PNAS 112: 8684-8689.

Simões M, Breitkreuz L, Alvarado M, Baca S, Cooper JC, Heins L, Herzog K, Lieberman BS (2016) The evolving theory of evolutionary radiations. Trends in Ecology \& Evolution 31: 27-34.

Simpson GG (1944) Tempo and Mode in Evolution. Columbia University Press, New York, USA.

Simpson GG (1953) The Major Features of Evolution. Columbia University Press, New York, USA.

Stamatakis A (2014) RAxML version 8: a tool for phylogenetic analysis and post-analysis of large phylogenies. Bioinformatics 30: 1312-1313.

Steppan SJ, Storz BL, Hoffmann RS (2004) Nuclear DNA phylogeny of the squirrels (Mammalia: Rodentia) and the evolution of arboreality from c-myc and RAG1. Molecular Phylogenetics and Evolution 30: 703-719.

Strassburg BBN, Rodrigues ASL, Gusti M, Balmford A, Fritz S, Obersteiner M, Kerry Turner R, Brooks TM (2012) 
Impacts of incentives to reduce emissions from deforestation on global species extinctions. Nature Climate Change 2: 350-355.

Strömberg CAE (2011) Evolution of grasses and grassland ecosystems. Annual Review of Earth and Planetary Sciences 39: 517-544.

Sullivan J, Demboski JR, Bell KC, Hird S, Sarver B, Reid N, Good JM (2014) Divergence with gene flow within the recent chipmunk radiation (Tamias). Heredity 113: 185-194.

Thorington RW, Miller AML, Anderson CG (1998) Arboreality in tree squirrels (Sciuridae). In: Steele MA, Merritt JF, Zegers DA (eds) Ecology and Evolutionary Biology of Tree Squirrels, 119-130. Virginia Museum of Natural History, Pittsburgh, Pennsylvania, USA.

Urban MC (2015) Accelerating extinction risk from climate change. Science 348: 571-573.

Van der Made J (1999) Intercontinental relationship EuropeAfrica and the Indian subcontinent. In: Rössner GE, Heissig K (eds) The Miocene Land Mammals of Europe, 457-472. Verlag Dr. Friedrich Pfeil, München, Germany.

Van Valen L (1971) Adaptative zones and the orders of Mammals. Evolution 25: 420-428.

Vianey-Liaud M (1974) Palaeosciurus goti nov. sp., écureuil terrestre de l'Oligocène moyen du Quercy: donnés nouvelles sur l'apparition des Sciuridés en Europe. Annales de Paléontologie (Vertébrés) 60: 103-122.

Villalobos F, Cervantes-Reza F (2007) Phylogenetic relationships of Mesoamerican species of the genus Sciurus (Rodentia: Sciuridae). Zootaxa 1525: 31-40.

Voloch CM, Vilela JF, Loss-Oliveira L, Schrago CG (2013) Phylogeny and chronology of the major lineages of New World hystricognath rodents: insights on the biogeography of the Eocene/Oligocene arrival of mammals in South America. BMC Research Notes 6: 160.

Vrba ES (1987) Ecology in relation to speciation rates: some case histories of Miocene-Recent mammal clades. Evolutionary Ecology 1: 283-300.

Vrba ES (1992) Mammals as a key to evolutionary theory. Journal of Mammalogy 73: 1-28.

Vrba ES (1995) On the connections between paleoclimate and evolution. In: Vrba E, Denton G, Patridge T, Burcke L (eds) Paleoclimate and Evolution, with Emphasis on Human Origins, 24-45. Yale University Press, New Haven, Connecticut, USA.

Vrba ES (1999) Habitat theory in relation to the evolution in African Neogene biota and hominids. In: Bromage TG, Schrenk F (eds) African Biogeography, Climate Change, and Human Evolution, 19-39. Oxford University Press, Oxford, UK.

Walter H (1970) Vegetationszonen und Klima. Verlag Eugen Ulmer, Stuttgart, Germany.
Wauters LA, Amori G, Aloise G, Gippoliti S, Agnelli P, Galimberti A, Casiraghi M, Preatoni D, Martinoli A (2017) New endemic mammal species for Europe: Sciurus meridionalis (Rodentia, Sciuridae). Hystrix 28: $1-8$.

Zachos, J, Pagani, M, Sloan, L, Thomas, E, Billups, K (2001) Trends, rhythms, and aberrations in global climate 65 Ma to present. Science 292: 686-693.

Zelditch ML, Li J, Tran LAP, Swiderski DL (2015)

Relationships of diversity, disparity, and their evolutionary rates in squirrels (Sciuridae). Evolution 69: 1284-1300.

\section{SUPPORTING INFORMATION}

Additional supporting information may be found in the online version of this article at the publisher's web-site.

Appendix S1. List of sequences wrongly assigned to Sciuridae in GenBank.

Appendix S2. List of the accession numbers in GenBank for all the sequences used in the phylogenetic inference. Appendix S3. Detailed information and references for calibrations.

Appendix S4. Distribution of biomes and biogeographic realms used in this work.

Appendix S5. Percentage of species included in trait categories and in the phylogeny.

Appendix S6. Bayesian inference and maximum likelihood topology comparison.

Appendix S7. Bayesian phylogenetic reconstruction.

Appendix S8. Maximum likelihood phylogenetic reconstruction.

Appendix S9. Ages inferred for the initial diversification of major lineages of Sciuridae.

Appendix S10. Calibration points in the phylogeny.

Appendix S11. Results of state-dependent analyses for the degree of specialisation.

Appendix S12. Results of state-dependent analyses for mountainous and lowlands species.

Appendix S13. Results of state-dependent analyses for the biogeographic realm occupancy.

Appendix S14. Results of state-dependent analyses for the locomotion modes.

Appendix S15. Ancestral reconstruction of the degree of specialisation.

Appendix S16. Ancestral reconstruction of the mountain occupancy.

Appendix S17. Ancestral reconstruction of the biogeographic realm occupancy.

Appendix S18. Ancestral reconstruction of the locomotion modes. 